\title{
CUIDADO TERAPÊUTICO LÚDICO EM UMA UNIDADE DE SAÚDE DO SUS: RELATO DE PESQUISA
}

\section{LUDIC THERAPEUTIC CARE IN A SUS HEALTH UNIT: RESEARCH REPORT}

\section{ATENCIÓN TERAPÉUTICA LÚDICA EN UNA UNIDAD DE SALUD DE SUS: INFORME DE INVESTIGACIÓN}

\author{
Isabel Cristina dos Santos 1 \\ Yolanda Flores e Silva2
}

\begin{abstract}
RESUMO Pensando em um cuidado humanizado, vários serviços de saúde vêm realizando a Arte Gestacional durante o pré-natal. Nesse contexto, este artigo teve o objetivo de "descrever as representações sociais de gestantes sobre a Arte Gestacional e suas implicações no que se refere à humanização do serviço através de um cuidado terapêutico diferenciado". A metodologia foi qualitativa com entrevistas às gestantes de uma unidade de saúde pública em um município do litoral catarinense. A análise dos dados foi realizada utilizando-se do processo de categorização dos conteúdos das entrevistas associadas às experiências de distintos pesquisadores e à experiência do serviço. A Teoria das Representações Sociais de Moscovici serviu de apoio teórico-metodológico para compreensão do universo dessas gestantes. Os resultados apontam que a AG se revela um cuidado terapêutico lúdico, auxiliando a gestante nos enfrentamentos cotidianos, fortalecendo vínculos entre mulher/família/bebê.
\end{abstract}

PALAVRAS-CHAVE: Cuidado Pré-Natal. Educação. Gestante. Promoção da Saúde.

ABSTRACT: With humanized care in mind, various health services have been offering Gestational Art during prenatal care. This article aims to "describe the social representations of pregnant women in relation to Gestational Art and its implications for the humanization of the service through a differentiated therapeutic care". The methodology used was qualitative, with interviews with pregnant women who attended a public health unit in a coastal city of Santa Catarina. The data analysis was performed using the process of categorization of the content of the interviews, associated with the experiences of different researchers and the experience of the service. Moscovici's Theory of Social Representations provided theoretical and methodological support for understanding the universe of these pregnant women. The results show that GA is a ludic, therapeutic care that helps pregnant woman face daily struggles, and strengthens the bonds between woman/family/baby.

Licença CC BY:

Artigo distribuído sob os termos Creative Commons, permite uso e distribuição irrestrita em qualquer meio desde que o autor credite a fonte original.
1 Mestre em Saúde e Gestão do Trabalho pela UNIVALI; Especialista em Saúde da Família - ISEPE - Especialista em Saúde Mental e Atenção Psicossocial - Escola de Saúde Pública - SC; Preceptora da Residência Multiprofissional em Saúde da Família: isabelcristina@itapema.sc.gov.br.

2 Pós-Doutora em Turismo [Desenvolvimento Local Comunitário] - UALg/Portugal; Doutora em Enfermagem [Filosofia da Saúde] - UFSC; Mestre em Antropologia Social - UFSC Docente/ Pesquisadora da UNIVALI: yolanda@univali.br. 
KEY WORDS: Education. Health Promotion. Prenatal Care. Pregnant Women.

RESUMEN: Pensando en la atención humanizada, varios servicios de salud han estado realizando arte gestacional durante la atención prenatal. En este contexto, este artículo tuvo como objetivo "describir las representaciones sociales de las mujeres embarazadas sobre el arte gestacional y sus implicaciones con respecto a la humanización del servicio a través de una atención terapéutica diferenciada”. La metodología fue cualitativa con entrevistas con mujeres embarazadas de una unidad de salud pública en una ciudad de la costa de Santa Catarina. El análisis de datos se realizó utilizando el proceso de categorización del contenido de la entrevista asociado con las experiencias de diferentes investigadores y la experiencia del servicio. La teoría de las representaciones sociales de Moscovici proporcionó apoyo teórico y metodológico para comprender el universo de estas mujeres embarazadas. Los resultados muestran que a AG es una atención terapéutica lúdica que ayuda a la mujer embarazada en confrontaciones diarias, fortaleciendo los lazos entre mujer / familia / bebé.

PALABRAS CLAVE: Atención prenatal. Educación. Mujer embarazada Promoción de la salud.

\section{O CONTEXTO DA PESQUISA}

A pesquisa realizada sob a ótica da Teoria das Representações Sociais de Serge Moscovici buscou caracterizar as representações sociais da Arte Gestacional, também conhecida como 'Ultrassom Natural' ou 'Ecografia Ecológica', para a gestante e sua família. Esta é uma abordagem reconhecida como sociopsicológica por Moscovici (1995) com bases na Sociologia Clássica e na Antropologia de Durkheim e Lévy-Bruhl. De modo geral, os teóricos clássicos da Sociologia e Psicologia Social entendem as representações sociais como categorias de pensamento que expressam a realidade social e/ou o cotidiano do saber leigo (SANTOS; DIAS, 2015).

Na área da saúde, a Teoria das Representações Sociais tem sido amplamente empregada com a intenção de considerar o conhecimento não especializado, o conhecimento leigo e as concepções de diversos grupos sociais, com a intenção de lidar com a complexidade dos problemas que as pessoas trazem às unidades de saúde (SILVA; CAMARGO; PADILHA, 2011). A partir deste contexto, de reconhecer o 'saber', 'o falar' e o 'pensar' leigos, é que pensamos em trabalhar na perspectiva das representações sociais construídas pelos sujeitos, como "conhecimentos práticos que se desenvolvem nas relações do senso comum, formados pelo conjunto de ideias da vida cotidiana, construída nas relações estabelecidas entre sujeitos ou através das interações grupais" (MOSCOVICI, 2002, p.12).

Com os pressupostos oriundos do pensamento de Moscovici, acreditamos ser essencial o estudo das concepções teóricas, sociológicas e psicológicas que influenciam a construção dos estudos com uso da Teoria das Representações Sociais, cujas bases são as obras de Durkheim (2007), Weber (2002) e do próprio Moscovici (2011; 2002; 1995), entre outras referências.

A Arte Gestacional, frente às múltiplas demandas na vida da gestante(trabalhos diários estafantes, família distante, falta de um companheiro mais presente, solidão, entre outros elementos), parece ser um cuidado importante, algo que foge da rotina convencional das consultas realizadas durante o pré-natal. A Arte Gestacional, além de mudar o olhar da gestante acerca da consulta do pré-natal, pode trazer benefícios importantes quanto aos aspectos emocionais e aos vínculos que estabelece com a Unidade de Saúde e os profissionais com quem precisa se relacionar até o parto e após o nascimento de sua criança. A Arte Gestacional é também conhecida como 
Ultrassom Natural, Ecografia Natural ou Ecografia Ecológica. Teve seu início na década de 1990 com a parteira mexicana Naoli Vinaver:

Naoli Vinaver Lopez é uma parteira mexicana que combina a prática do parto tradicional com um profundo interesse e respeito pela psicologia e a fisiologia do parto. Desde 1987 ela atendeu por volta de 1000 partos domiciliares em sua região (Xalapa, Veracruz, México), além de participar como conferencista em congressos sobre parto em mais de 30 países. Naoli teve três filhos em partos domiciliares acompanhada de sua família, o último dando origem ao vídeo "Dia de Nascimento". (WOLFAT, 2012a, p. 9).

Embora para Naoli Vinaver seu trabalho fundamental esteja relacionado ao parto, o acompanhamento das gestantes ocorre com vários encontros e a Arte Gestacional, realizada a princípio para firmar vínculos entre a parteira e a gestante, terminou se tornando um modelo de cuidado que no Brasil vem sendo usado em vários serviços de saúde. Este cuidado 'artístico' e lúdico pode ser considerado uma tecnologia de saúde do tipo leve, isto porque:

Permite a produção de relações envolvidas no encontro trabalhador-usuário mediante a escuta, o interesse, a construção de vínculos, de confiança; mediante processos micropolíticos de encontros que operam como acontecimentos e imprevisíveis a priori, por isso, essa terceira conformação das tecnologias leves é um ponto poroso da produção do cuidado, é onde o agir tecnológico se abre para um acontecer não tecnológico. (MERHY; FEUERWERKER, p. 66).

Esta arte, que as autoras realizaram em uma unidade de saúde do SUS, é uma pintura realizada na barriga da gestante, em que, por meio da palpação e do toque (Manobra de Leopold), identifica-se a posição do bebê para que possamos fazer uma pintura do mesmo na barriga da mãe (WOLFAT, 2012b). Ser tocada em um momento como este pode ser considerado algo especial, e quando o toque não é encarado apenas como uma manipulação mecânica, "representa uma expressão de participação da cuidadora na experiência do paciente" (WALDOF, 2004, p. 157).

No Brasil, este cuidado vem sendo realizado na área da saúde por Enfermeiros, Psicólogos, Agentes Comunitários de Saúde, entre outros profissionais. A pintura no ventre materno "é uma atividade artística utilizada como forma de expressão do bebê e da gestação, podendo promover experiências maternas subjetivas sobre conhecer / interagir / aproximar / proteger o bebê e disposição para evitar a separação/perda” (FUJITA; SHIMO, 2016, p. 440).

A Arte Gestacional deve ser realizada com o consentimento da mãe e até mesmo de outros familiares, sempre que possível com a presença de sua família. Saber o que ela pensa sobre este processo, o que sabe ou o que concebe deste momento e inclusive que sentimentos esta ação lhe traz, é uma das propostas deste tipo de arte. Acreditamos que a pesquisa realizada pode mostrar um pouco deste momento e ao mesmo tempo demonstrar que é possível humanizar mais o pré-natal, e utilizar este tipo de abordagem como um cuidado imprescindível e importante no sentido de trazer mais mulheres às consultas. $\mathrm{O}$ trabalho de Vinaver abre também a perspectiva de olharmos a gestação como fenômeno que não precisa ser atrelado ao medo e à dor. É possível empoderar as mulheres gestantes para que vivam este momento com mais risos e tranquilidade (GOTARDO, 2018). 
Um pré-natal mais humanizado que possa estabelecer com a gestante e sua família uma relação mais harmoniosa e lúdica poderá ser um dos caminhos possíveis para a diminuição das faltas às consultas do pré-natal e também como espaço de aprendizado. Neste sentido, o Ministério da Saúde lançou, por meio da Portaria/GM n ${ }^{\circ}$ 569, de 01 de junho de 2000, o Programa de Humanização no Pré-natal e Nascimento (PHNP), tendo como principal objetivo assegurar a melhoria do acesso, cobertura e qualidade do acompanhamento prénatal, da assistência ao parto e ao puerpério às gestantes e ao recém-nascido, na perspectiva dos direitos de cidadania (BRASIL, 2002).

Este programa tem dois aspectos fundamentais, o primeiro é o dever de as unidades de saúde receberem com dignidade as mulheres, os seus familiares e o recém-nascido, criando um ambiente mais acolhedor; o segundo diz respeito a medidas e procedimentos sabidamente benéficos para o acompanhamento do parto e do nascimento. Seguindo essa lógica de humanização, o Ministério da Saúde lançou também, por meio da Portaria 1.459, de 24 de junho de 2011, a Rede Cegonha, com quatro componentes, que são o pré-natal, o parto e nascimento, o puerpério e a atenção integral à saúde da criança e ao sistema logístico com transporte sanitário e regulação (BRASIL, 2002).

A Rede Cegonha veio no sentido de reforçar a necessidade de criação de vínculo entre gestante, família, profissional da saúde e unidade básica de saúde, garantindo boas práticas no atendimento do pré-natal. Consideramos a Arte Gestacional uma das boas práticas que o profissional pode ofertar para o cuidado com a gestante e família nesta rede que também poderá ser importante no sentido de incentivar a participação do pai no processo de gestação. Sabemos que as gestantes, cujos parceiros participaram das atividades de educação para a saúde no prénatal, apresentaram comportamentos melhores em relação ao cuidado do que àquelas que não puderam contar com esta adesão (REBERTE; HOGA, 2010).

É de suma importância o encorajamento da participação do pai durante as consultas e ações educativas que ocorrem na unidade, assim como no parto. Durante a consulta pré-natal realizada por enfermeiras(os), esta é uma das premissas do cuidado que tem por objetivo minimizar dúvidas e anseios para que a mulher tenha uma gestação saudável, pois além das informações técnicas, almeja-se aumentar o vínculo entre o enfermeiro, a gestante e sua família. A enfermagem é uma profissão essencialmente ligada ao cuidado e em função deste contexto, precisa atender com um olhar mais empático. Trabalhar nesta perspectiva é buscar a realização de um cuidado com mais envolvimento, o que para muitos significa um cuidado integral às pessoas assistidas (LIMA, 2013), um cuidado que se revela muito mais como arte do que como técnica (BOFF, 2013).

No contexto da gravidez, o cuidado que o enfermeiro deve prestar no pré-natal pode centrar-se no acolhimento e na criação de vínculos com a gestante e sua família. É um momento de ouvir e de ser solidário com as preocupações, as angústias e as ansiedades da gestante, levando em consideração não somente as questões biológicas, mas todas as questões envolvidas no processo de gestação, mudanças psicológicas, e até mesmo as dificuldades econômicas que a família possa estar enfrentando no momento. Este cuidado associado com a Arte Gestacional é fundamental, como um processo, um modo de se relacionar, deixando espaços abertos para o desenvolvimento de confiança mútua, provocando uma profunda e qualitativa transformação no relacionamento com as gestantes (WALDOW, 2004). 
Considerando todo este contexto, o objetivo geral norteador da investigação realizada foi o de "descrever as representações sociais de gestantes sobre a Arte Gestacional e suas implicações no que se refere à humanização do serviço através de um cuidado terapêutico diferenciado”. Os caminhos metodológicos para alcançarmos este objetivo estão descritos no tópico a seguir.

\section{O PERCURSO REALIZADO PARA A EFETIVAÇÃO DA PESQUISA}

Essa é uma pesquisa com abordagem qualitativa e aporte da Teoria das Representações Sociais (RS) de Moscovici. Para ele:

As representações sociais são conhecimentos práticos que se desenvolvem nas relações do senso comum, formados pelo conjunto de ideias da vida cotidiana, construída nas relações estabelecidas entre sujeitos ou através das interações grupais. (MOSCOVICI, 2011, p. 23).

As Representações Sociais buscam entender o comportamento dos indivíduos, grupos e sociedade baseando-se no senso comum e representações do cotidiano dos próprios sujeitos. Para Durkheim, as representações são elaboradas de uma forma coletiva, e desse modo o autor fez uma ruptura entre o coletivo e o individual, entendendo o indivíduo como produto de sua realidade social e de uma consciência coletiva (JODELET, 2001). Nesse contexto de estudos, Moscovici apresenta sua teoria sobre as representações sociais com algumas modificações com relação à teoria de Durkheim. Ele substitui o termo coletivo pelo social, pois para ele, embora as representações aconteçam de forma coletiva, não é possível ter uma representação coletiva sem que antes exista uma representação individual (MOSCOVICI, 2011; JODELET, 2001).

As representações materializadas no senso comum adquirem "vida" própria como produto da atividade social e uma das funções das Representações Sociais é tornar o desconhecido em conhecido, fazer com que o que até então não era conhecido se torne visível. Moscovici, neste sentido, tenta mostrar uma nova forma de fazer ciência, ou seja, a ciência aceitando o "comum" como parte da sua construção (MOSCOVICI, 1995).

E por que percorrer este caminho teórico para esta investigação? Porque a investigação teve como foco descrever alguns aspectos subjetivos do cotidiano de mulheres gestantes que aceitaram participar de um cuidado terapêutico denominado neste trabalho de Arte Gestacional. Ou seja, o trabalho foca a descrição dos sentimentos, das crenças e das percepções pessoais de mulheres gestantes. Lembrando que, em sua maioria, são migrantes, donas de casa e/ou trabalhadoras em residências ou empresas de limpeza. Seja no serviço externo ou em casa, todas falaram da falta de tempo para parar, olhar para si ou mesmo conversar sobre seus medos e dúvidas.

Os procedimentos técnicos adotados seguiram a perspectiva do Estudo de Caso, um "estudo profundo e exaustivo de um ou mais conhecimentos amplos e detalhados de um fato ou fenômeno" (GIL, 1987, p. 78), realizado com um grupo escolhido de forma proposital. Importante enfatizar que, face às características da abordagem qualitativa, poderia ser permitida a entrada de outros informantes no grupo preexistente, se estes fossem considerados importantes como elementos capazes de contribuir para ampliar o conhecimento que tínhamos como objetivo (YIN, 2009). 
Para a coleta de dados, utilizamos um roteiro de entrevistas semiestruturadas com perguntas abertas e flexíveis para que as entrevistadas se sentissem à vontade para expressar seus sentimentos e ideias. As entrevistas foram gravadas e posteriormente transcritas com a devida autorização das participantes.

A análise dos dados coletados foi realizada utilizando-se a técnica de categorização temática de Minayo (2014) para organização dos dados transcritos, compreendendo uma leitura corrida das entrevistas seguida de uma leitura mais reflexiva para organização das informações, considerando os objetivos da pesquisa. Após esta etapa de organização sistemática das informações, fizemos a análise teórica com reflexões considerando-se o ponto de vista das informantes, dos pesquisadores e dos referenciais bibliográficos. A pesquisa foi realizada em um município localizado no Litoral Norte do Estado de Santa Catarina. Com relação aos serviços de saúde ofertados nesse município, além de uma estrutura privada, existe a estrutura do SUS com 10 Unidades Básicas de Saúde e 14 Equipes de Estratégia da Saúde da Família (ESF), 01 Núcleo de Apoio à Saúde da Família (NASF) e um hospital.

Neste município selecionamos um dos bairros cuja Unidade Básica de Saúde tem o3 Equipes de Estratégia da Saúde da Família para a pesquisa. São acompanhadas nessa unidade cerca de 100 gestantes por mês. As gestantes que foram inclusas como informantes foram as que: passaram pela experiência da Arte Gestacional, tinham 30 semanas ou mais de gestação e faziam acompanhamento regular de pré-natal, e aceitaram participar da pesquisa. Dentre as 100 gestantes assistidas mensalmente, fizemos contato com todas, mas a amostra final ficou em 9 gestantes, uma coleta aceitável em pesquisas qualitativas como a que nos propomos a realizar (GIBS, 2009).

Os primeiros 04 encontros realizados para as entrevistas foram feitos na Unidade Básica em lugar reservado com privacidade (consultório de enfermagem). Como as interrupções eram constantes e deixavam as gestantes tímidas e desconfortáveis, optamos por realizar os demais encontros nas casas das entrevistadas. Estas gestantes foram aquelas com quem tivemos contato em todo o processo de pré-natal. No caso específico da investigação, além das entrevistas com as gestantes, resolvemos incluir alguns depoimentos informais da Parteira Naoli Vinaver, profissional que iniciou no México essa técnica de pintura na barriga e que hoje atua com formações e grupos diversos na capital Catarinense. Estas inclusões estão em momentos da análise com palavras dela ou de pesquisadores que escreveram sobre ela.

Por se tratar de uma pesquisa que envolveu seres humanos, tomamos todos os cuidados éticos previstos na Resolução 510 de 07 de abril de 2016 e Resolução 466 de 12 de dezembro de 2012. Antes de iniciarmos a pesquisa, esta foi submetida ao Conselho de Ética em Pesquisa da universidade e foi aprovada em 31 de outubro de 2017 (parecer número 2.341.909). Importante: este artigo é uma síntese de alguns resultados da pesquisa realizada para elaboração da dissertação "REPRESENTAÇÕES SOCIAIS DA ARTE GESTACIONAL PARA A GESTANTE E SUA FAMÍLIA”. 


\section{O OLHAR E OS DISCURSOS: O QUE É ARTE GESTACIONAL?}

A antropóloga e parteira tradicional Naoli Vinaver é conhecida no México; em Florianópolis, onde reside; assim como em outros países onde realiza anualmente formações, pelo trabalho humanizado que realiza com gestantes no acompanhamento de pré-natal e parto em sua grande maioria domiciliar. A Arte Gestacional (nome adotado neste trabalho) é também conhecida como Ultrassom Natural (denominação de Naoli Vinaver) ou Ecografia Ecológica (denominação de pesquisadores que trabalham com parto humanizado). A origem deste cuidado e/ou tecnologia leve teve seu início com a Naoli Vinaver na década de 1990, quando esta atuava como parteira em comunidades camponesas no México (WOLFAT, 2012ª).

As mulheres mexicanas atendidas pela parteira Naoli no meio rural não tinham acesso a nenhum tipo de tecnologia durante o acompanhamento pré-natal devido à dificuldade de chegarem até os grandes centros do México, onde havia acompanhamento médico e exames. Estas mulheres moravam em vilas pequenas com difícil acesso a qualquer infraestrutura de saúde. A tradição de parteiras nessas localidades já existia de longa data no atendimento às gestantes. Sobre como esta parteira mexicana iniciou com a 'Arte Gestacional', temos um relato de entrevista realizada em 2017 e outros de textos que estão em sua rede social:

(... ) ai veio à questão: ao mesmo tempo que eu acompanhava o parto na roça, começaram a me procurar também na cidade, para realizar parto de mulheres que tinham a opção de ir para o hospital mas queriam parir em casa, aí eu fui acompanhando umas e outras e acabou sendo uma população de 50\% de mulheres da zona urbana e 50\% da zona rural. Então claro que as mulheres da cidade tinham como fazer ultrassom, mas as do campo não. (...) então o Ultrassom Natural nasceu em parte dai, porque eu ficava assim, gente, se uma mulher da cidade vai fazer um ultrassom e consegue ver sua criança, como fazer o mesmo com a mulher do campo? Quando apalpava a barriga da mãe, eu queria também explicar para ela como que estava a sua criança, a posição, o tamanho, sabe, então eu comecei a querer compartilhar meus conhecimentos que também fazem parte de uma filosofia mais oriental (...) (Vinaver, 2017).

Eram momentos especiais, não apenas um momento em que falávamos da criança, mas, surgiam ali outras questões. $O$ medo, a incerteza, o constrangimento e ao mesmo tempo muita esperança. Aquele ultrassom realizado com tintas, toques em um ambiente de trocas entre mulheres, servia também como fonte de apoio né? Então eu pensei comigo, vou fazer com todas as mulheres, mesmo as que podem na cidade ter acesso ao ultrassom convencional. (VINAVER, 2018).

Os sentimentos de Naoli Vinaver sobre as mulheres que não tinham acesso ao ultrassom também se fazem sentir em unidades de saúde, cuja realização deste exame pode demorar a tal ponto que, fazer a AG substitui a frustração de não fazer o exame e ao mesmo tempo é visto como 'mais bonito' e especial para muitas gestantes. Embora não se tenha registro de quando essa técnica chegou ao Brasil, nos últimos 10 anos esse cuidado terapêutico vem sendo bastante divulgado nos meios de comunicação como jornais, televisão e também na internet por meio de redes sociais. 
Na unidade de saúde onde a investigação ocorreu, 100 gestantes foram convidadas a participar da pesquisa, destas, 9 aceitaram responder algumas questões sobre si mesmas e o significado da Arte Gestacional para elas. Todas as gestantes entrevistadas relataram que foi a primeira vez que elas tiveram contato com esse trabalho, que não conheciam anteriormente, e que ficaram sabendo da pintura quando iniciaram o pré-natal. Sobre estas mulheres constatamos que:

Quadro 1: Perfil das gestantes participantes

\begin{tabular}{c|c} 
Características & Número de Gestantes \\
\hline Idade gestante mais jovem & 16 anos \\
\hline Idade gestante mais velha & 41 anos \\
\hline Casadas & 2 \\
\hline União estável & 7 \\
\hline Gravidez planejada & 8 \\
\hline Gravidez não planejada & 3 \\
\hline Que já tiveram aborto & 6 \\
\hline Que nunca tiveram aborto & 4 \\
\hline Trabalham fora de casa & 5 \\
\hline Do lar & 4 \\
\hline Com ensino médio completo & 1 \\
\hline Com ensino médio incompleto & 1 \\
Com ensino fundamental incompleto &
\end{tabular}

A Representação Social é uma forma de conhecimento resultante do senso comum, compartilhado, elaborado e construído socialmente a partir da realidade comum de pessoas que se interligam ou interagem em certo grupo social (MOSCOVICI, 2011; JODELET, 2001). Sobre a Arte Gestacional e suas representações, as gestantes afirmaram que trazem a elas várias sensações, tais como: 
Figura 01: Representações da Experiência da AG

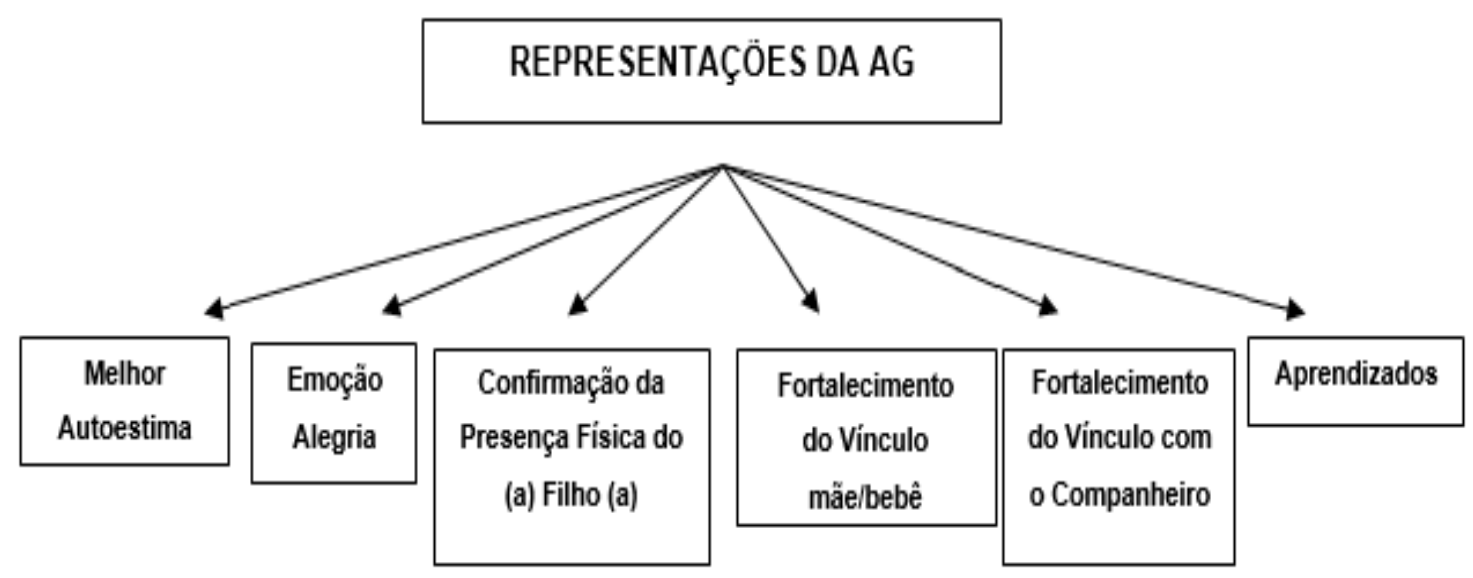

Fonte: Dados de Pesquisa (2018)

Nestas representações também vieram à tona a gestação como um momento único repleto de vários sentimentos que muitas vezes são ambivalentes, este universo é expresso nos discursos das gestantes, algumas vezes como alegria e em outras como incerteza. Este contexto, que Rezende (2011, p. 323) afirma ser com "tensões tanto para a individualidade da gestante quanto para suas relações familiares”, foi citado por todas as gestantes. Os mais referidos estavam ligados à autoestima, algo que é mais comum do que imaginamos. A autoestima tanto pode estar relacionada com fatores internos quanto externos. Os externos se referem ao próprio corpo, o achar-se bonita, especial, capaz de gerar uma criança e ao mesmo tempo permanecer mulher. Nos depoimentos, é possível perceber como cada mulher percebe este momento em que se realiza a pintura em suas barrigas:

(...) a gente fica olhando e imaginando como tudo isso foi possível, nossa... é muito legal. Aumenta o poder da gente em alguns momentos e diminui em outros. Às vezes dá vontade de ter mais filhos (risos)... A gente não quer mais tirar da barriga. Esta pintura dá a impressão que nossa criança está nos olhando sabe, parece que a gente vê o bebe ali por fora. Nossa, é muito legal! (A. F. G. S, 39 anos).

As gestantes relatam também sobre a emoção de ver o desenho que representa o filho ou a filha que vai nascer, para elas é um momento que remete ao bem-estar e à felicidade fatores, importantes para a autoestima e, consequentemente, para uma gestação mais tranquila. Isto é importante, porque "o fato de a gestante manifestar prazer e entusiasmo por comportamentos como acariciar a barriga e conversar com o bebê evidencia o apego materno-fetal” (ALVARENGA et al, 2012, p. 478). Nesse sentido, consideramos a AG um desenho que de uma forma indireta faz a gestante em seu cotidiano atribulado de trabalho ter contato com o bebê ainda dentro do útero e ao mesmo tempo iniciar 'pontes' de apego, de carinho e de cuidado. 
(...) nem todas as mães planejaram engravidar, mais ali quando tem esse elo que você vê uma tripinha, posso dizer assim no sentido popular, você vê ali que tem algo interligado com você, né, e é único é um simples desenho que faz uma grande diferença (D. S. M, 34 anos).

Nas falas, a pintura remete ao 'real', uma criança imaginada se torna mais concreta na medida em que observam a representação em desenho do que ela pode vir a ser. O fato do bebê se mexer bastante durante a pintura fez com que uma das gestantes relacionasse este movimento como uma demonstração de aceitação. Como se esta estivesse interagindo com ela durante a pintura.

(...) é bonito, é colorido, é uma coisa diferente (...) ter a sensação de como o bebê está na barriga, sei lá, legal, achei bonito (...) eu senti ela mexer (risos), parecia que ela tava mais feliz que eu. (J. S. M, 28 anos).

Na Arte Gestacional, a interação da gestante durante o processo da pintura é muito importante, seus desejos, anseios e expectativas são extremamente relevantes nas decisões tomadas acerca de cada traço feito em sua barriga. É também um momento de respeito pela emoção que extravasa, seja em lágrimas ou risos, como podemos perceber na fala a seguir.

Dá uma alegria, assim de repente do nada, dessa alegria você vai querendo também fazer parte, mesmo sem saber como é que funciona aquele desenho, você quer fazer parte, você fica dando sugestões, assim como eu fui dando sugestões para as meninas - faz um lado mais de hominho que fica parecido com o pai, com bola, com time de futebol, aí faz o outro lado com o jeito da mãe - então você vai de certa maneira também sendo influenciada naquilo, você quer também participar, muito bom (...) só de estar fazendo ali é único, é muito bom, você sente algo bom sabe, a cada pincelada que vocês dão significa muito pra gente. (D. S. M, 34 anos).

O vínculo entre mãe / bebê parece fixar-se mais ainda após o desenho, embora elas relatem que durante o crescimento do feto no útero, elas sentiam a criação de laços e amor, algo que é de estrema importância para a futura mamãe e seu bebê. Porém, nem sempre isso é fácil, pois existem vários fatores físicos e emocionais que podem interferir nesse processo, como o planejamento ou não da gravidez, as condições socioeconômicas, o apoio da família, estar vivendo harmonicamente com o pai da criança, entre outros elementos.

Para Rezende (2011), estes são fatores importantes para a formação do vínculo entre pais e bebê: planejamento e aceitação da gravidez, e isto ocorre com a conscientização dos movimentos do feto, a percepção deste como uma pessoa separada, a vivência do trabalho de parto, o nascimento, o tocar e o cuidar do bebê, aceitando-o como parte da família. No caso das gestantes deste estudo, a criação deste vínculo, segundo elas, se solidificou também em função da AG. Olhar e tocar a barriga com carinho e observar toda a família e vizinhos curiosos, com vontade de estar com ela, também foram importantes e bastantes representativos.

Este momento em que, por meio da AG, se tenta estabelecer uma ponte entre mãe e filho(a) como de extrema significação para "a construção do vínculo entre mãe e filho, a vivência de experiências subjetivas que integram o núcleo subjetivo da vinculação ou experiência do amor" (FUJITA; SHIMO, 2016, p. 440) se fez sentir em depoimentos como este: 
(...) é um trabalho que incentiva as mães. A mãe às vezes tá rejeitando a criança ou tá deprimida e fazendo um desenho assim incentiva a mãe sabe, não em fazer mais filho, em fazer mais filho não, mais incentiva de querer tá com ele no colo, sabe de querer dar amor, carinho desde ali na barriga. (V. P. L, 41 anos).

Foi possível durante a pintura e depois na entrevista, perceber uma série de emoções a transparecer no rosto, quando puderam visualizar o desenho pronto. Algumas expressaram o desejo em dividir esse momento com outras pessoas da família e até mesmo com os profissionais de saúde que estavam na unidade de saúde onde o procedimento foi realizado. Uma delas, entrevistada alguns dias após este cuidado, expressou:

Há quase corri pra mostrar ao pai, já que ele não tava presente e é a única pessoa que eu tenho aqui. Deu vontade de correr pro pai, se não for pro pai, pra alguém e antes disso é tirar foto é registrar como se fosse um passo a passo sabe. Então eu chamei a (...), chamei o Dr. (...) e fomos saindo tirando foto com quem eu vi na frente (risos). (D. S. M, 34 anos).

A participação do companheiro e dos familiares sempre foi citada como muito importante durante o pré-natal e na unidade onde atuamos, o que vem sendo cada dia mais incentivada por meio de políticas públicas. Com a $\mathrm{AG}$ não é diferente, quando uma gestante é agendada para sua realização, incentivamos a participação do parceiro, dos filhos, dos familiares e até mesmo de amigos que a gestante considere importante ter ao seu lado. Não limitamos o número de pessoas que queiram participar e nem a idade, o único requisito para acompanhar é pintar junto e a gestante querer a presença dessas pessoas durante a pintura. $\mathrm{O}$ depoimento a seguir reflete um pouco o sentimento que a parteira Naoli sempre expressa nas suas formações: a partilha, o acompanhamento saudável das pessoas que dão suporte à gestante:

Então assim foram todos eles né, meu marido e as meninas, cada um que ia pintando parecia que ia desenhando ele. O pai disse que ele ia ser parecido com o pai (risos). Me senti protegida. (A. F. G. S, 39 anos).

Quando foram perguntadas sobre se tinha ocorrido alguma mudança em relação ao companheiro, uma das gestantes deu a seguinte resposta:

Mudou ele e mudou a minha cabeça também, mudou meu ponto de vista, porque a gente tava meio brigado né, e eu achava que ele tava brigando comigo por causa da minha gestação, mas não. E mudou também o meu ponto de vista, porque eu pude amar mais ela dentro da barriga. Antes eu cheguei a culpá-la pelos meus problemas. (V. P. L, 41 anos).

Outro fator importante da AG é que durante a pintura, que dura em média 40 minutos, as gestantes relaxam e muitas vezes parecem descansar do dia atribulado. $\mathrm{E}$ as que ficam alertas tiram dúvidas que se esqueceram de tirar durante as consultas de enfermagem ou médica, ou reforçam algum conhecimento adquirido durante as consultas e grupos. Isto nos confirma a AG como base para a aprendizagem, tendo um caráter educacional, como podemos observar a seguir: 
Parar para fazer este desenho foi muito bom. Descansei e ao mesmo tempo tirei dúvidas sobre como cuidar de minha criança e de mim. Fixou o cuidado. Esse cuidado com a criança na alimentação, sobre o que a gente come, porque tudo o que a gente come, bebe, passa na gestação passa tudo pra criança (...) as informações que vocês passam deixam a gente mais ciente e isso é muito importante. Cada parto é único, e até a pintura, o que vocês falam antes, parece que na pintura fica mais fixado, parece que se conclui, é como se cada passo da gestação, cada mês que se passa, é algo único para nós. A gente, a mulher, pode ter outros filhos e várias informações, mais ali ela quer buscar alguém que passe pra ela o que os outros lugares não conseguiram, e na pintura vem esse esclarecimento a mais. É realmente importante o que é falado. Sempre lembro da conversa sobre o cordão umbilical ali, que tá interligado, como a alimentação que passa através do cordão umbilical que vai pro neném, e aquele desenho remete isso à vida, à alegria, a satisfação. (D. S. M, 34 anos).

Nos depoimentos destas mulheres, bem como na fala da parteira Naoli, é bastante significativo entender como medidas simples podem se tornar importantes meios educacionais, bem como de interação e resolução de problemas de distintas naturezas. Os limites da própria pesquisa e do tempo que passamos ao lado das mulheres nos levaram a pensar que a AG pode, com estudos e por meio de uma proposta sobre como realizá-la e torná-la parte das dinâmicas do pré-natal, no futuro ser um cuidado terapêutico e uma tecnologia a se realizar em todas as consultas, caso as mulheres queiram e aceitem receber mais este cuidado afetivo, solidário e acolhedor.

\section{O QUE ESTE ESTUDO SIGNIFICOU}

Trabalhar com o senso comum exige muitas leituras de quem pesquisa para apreender alguns conhecimentos que não estão no cotidiano de nossas obrigações profissionais. E isto ocorre porque nos meios acadêmicos o conhecimento do senso comum tem pouca valia no cotidiano da ciência e/ou conhecimento científico. A pesquisa com abordagem qualitativa tend o como pano de fundo algumas respostas relativas ao senso comum de mulheres gestantes é um exemplo deste fenômeno contemporâneo de transcender as objetividades exigidas nas universidades. Foi com este olhar e nesta perspectiva que essa pesquisa aconteceu.

Os resultados das entrevistas nos mostraram que a Arte Gestacional é um cuidado terapêutico que, conforme o modo de realização, pode ser uma tecnologia leve, sem aporte da alta tecnologia, ou uma tecnologia social, quando a participação da gestante e a da família são de total proatividade. Em ambas as situações, este cuidado permite a aproximação da gestante com seu bebê ainda dentro do útero com estreitamento de vínculos. O momento é sempre de grande emoção, associado a aprendizados que podem ser importantes antes e depois do parto.

Nesse sentido, a pesquisa nos mostrou como a Arte Gestacional pode ser utilizada durante as consultas de enfermagem ou grupos de educação em saúde, com o intuito de humanizar o cuidado. Se bem aproveitado, quando os maridos podem participar do processo, pode ser o momento de uma maior interação destes homens com a unidade de saúde, suas mulheres e futuros filhos ou filhas. Também é um momento para orientações, tirar dúvidas, minimizar 
preocupações, tornando a gestante mais empoderada e protagonista do seu processo de gestar e parir.

Foi possível entender, por meio da pesquisa, que a Arte Gestacional é também um cuidado relevante como momento de trocas de natureza técnica, mas também como espaço de acolhimento para as gestantes. Consideramos que, se for concretizado nas consultas, tanto os profissionais quanto as gestantes ganharão um espaço de construção e fortalecimento de vínculo, acolhimento, ensino e aprendizagem. Esta arte, denominada de 'Ultrassom Natural' pela parteira Naoli Vinaver, foi a tecnologia que ela construiu para explicar a condição da criança que a gestante tinha em sua barriga. Se as mulheres do meio urbano tinham um ultrassom tecnológico, ela conseguiu apresentar um ultrassom que podemos considerar como uma forma suave de tecnologia realizada com tintas, manobras obstétricas e criatividade. Segundo partes da conversa que tivemos com ela em 2017, é importante pensar neste cuidado como algo que possa proporcionar momentos de acolhimento, intimidade e o vislumbre simbólico de uma criança às vezes sonhada e outras vezes não desejada em função das dificuldades comuns em lugares pobres e afastados da urbe. Durante este cuidado não é o momento de criticar ou criar momentos de tensão com a gestante. É o momento de deixar que cada gestante se sinta livre e segura para expressar o que lhe vier à mente.

No trabalho realizado em Santa Catarina em unidades do SUS, a Arte Gestacional vem sendo bastante divulgada por meio das redes sociais, e também no canal virtual que as prefeituras disponibilizam e, desta forma, onde não existe este cuidado, formações vêm sendo realizadas para que outras enfermeiras, assim como outros profissionais, possam implementar em seus municípios. $\mathrm{O}$ interesse e a perspectiva de ampliar as possibilidades de ofertar às gestantes a pintura associada a novos conhecimentos e reflexões sobre o processo saúde e doença, sobre a sua condição de mulher e gestante, entre outras temáticas, fortalecem a ideia de ampliar o que se realiza hoje nas unidades de saúde do litoral norte catarinense.

Com este estudo, esperamos contribuir para a discussão da Arte Gestacional como um cuidado de saúde. Poucos estudos tratam desta questão com relatos que possam não apenas mostrar o que é e como se faz, mas sobre os benefícios para a gestante e sua família. Incluí-la como um dos cuidados ou tecnologias possíveis à mulher no período gestacional de modo a torná-la uma política pública de aprendizado proativo com outros profissionais da saúde, as gestantes e seus familiares, é uma das metas que almejamos.

\section{REFERÊNCIAS}

ALVARENGA, Patricia; DAZZANI, Maria Vergínia Machado; ALFAYA, Cristiane Ajnamei Santos; LORDELO, Eulina Rocha; PICCININI, César Augusto. Relações entre a saúde mental da gestante e o apego materno-fetal. Estudos de Psicologia, v. 3, n. 17, p. 477-484, set. / dez. 2012. Disponível em: http:// www.scielo.br/pdf/epsic/v17n3/17.pdf. Acesso em: abril de 2018.

BOFF, Leonardo. O cuidado necessário: na vida, na saúde, na educação, na ecologia, na ética e na espiritualidade. 2. ed. Petrópolis: Vozes, 2013.

BRASIL. Humanização do parto: humanização do pré-natal e nascimento. Brasília: Ministério da Saúde, 2002.

DURKHEIM, Emile. As regras do método sociológico. São Paulo: Martins Fontes, 2007. 
FUJITA, Junia Aparecida Laia Mata.; SHIMO, Antonieta Keiko Kakuda. Representação social sobre a arte da pintura do ventre materno. In: Anais do Congresso Ibero-Americano em Investigação Qualitativa, Porto, $5-7$ de maio de 2016. Porto (Portugal): CIAIQ, 2016. (p:439-450). Disponível em: http://proceedings.ciaiq.org/index.php/ciaiq2016/article/view/781/768. Acesso em: abril de 2018.

GIBBS, Graham . Análise dos dados qualitativos. Porto Alegre: Artmed, 2009.

GIL, Antônio Carlos. Métodos e técnicas de pesquisa social. São Paulo: Atlas, 1987.

GOTARDO, Ana Tereza. Parto humanizado, empoderamento feminino e combate à violência: uma análise do documentário 'o renascimento do parto'. Doc. On-line, v.1, n. 23, p. 29 - 45, Jan. 2018. Disponível em: http://www.doc.ubi.pt. Acesso em: abril de 2018.

JODELET, Denise. As representações sociais. Rio de Janeiro: UERJ, 2001.

LIMA, Suzinara Soares. Enfermagem no pré-natal de baixo risco na estratégia saúde da família. Aquichan, v. 13, n. 2, p. 261-269, maio, 2013. Disponível em: http://www.scielo.org.co/pdf/aqui/v13n2/v13n2a12. pdf. Acesso em: maio de 2018.

KLAUS, Marshall; KENNELL, John; KLAUD, Phyllis. Vínculo: construindo as bases para um apego seguro e para a independência. Porto Alegre: Artmed, 2000.

MiNAYO, Maria Cecília Souza. O desafio do conhecimento. Pesquisa qualitativa em saúde. 14. ed. São Paulo: Hucitec, 2014.

MERHY, Emerson Elias; FEUERWERKER, Laura Camargo Macruz. Novo olhar sobre as tecnologias de saúde: uma necessidade contemporânea. In: MERHY, E.E. et al. (Org.). Avaliação compartilhada do cuidado em saúde: surpreendendo o instituído nas redes. Rio de Janeiro: Hexis, 2016. 448 p. (Políticas e cuidados em saúde; 1). Disponível em: www.hexiseditora.com.br . Acesso em: dezembro de 2018.

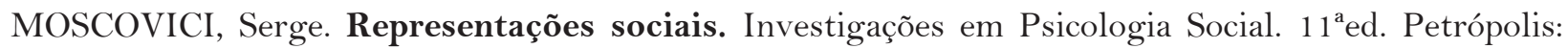
Vozes, 2011.

La representación social: un concepto perdido. Lima: IEP - Instituto de Estudios Peruanos, 2002. Disponível em: www.cholonautas.edu.pe.

. Prefácio. In: GUARESCHI, P.; JOVCHELOVITCH, S. (Org.). Textos em Representações Sociais. Petrópolis: Vozes, 1995.

REBERTE, Luciana Magnoni; HOGA, Luiza Akiko Komura. A experiência de pais participantes de um grupo de educação para saúde no pré-natal. Ciencia y Enfermeria, v. 16, n.1, p. 105 - 114, abril, 2010. Disponível em: https://scielo.conicyt.cl/pdf/cienf/v16n1/art_12.pdf. Acesso em: abril de 2018.

REZENDE, Claudia Barcellos. Um estado emotivo: a representação da gravidez na mídia. Cadernos Pagu, v. 36, n. 1, p. 315 -344, jan./jun. 2011 . Disponível em: http://www.scielo.br/pdf/cpa/n36/n36a12. pdf. Acesso em: abril de 2018.

SANTOS, Geovane Tavares; DIAS, José Manoel de Barros. Teoria das representações sociais: uma abordagem sociopsicológica. PRACS: Revista Eletrônica de Humanidades, v. 8, n. 1, p. 173 - 187, jan./ jun. 2015. Disponível em: http://periodicos.unifap.br/index.php/pracs. Acesso em: agosto de 2018.

SILVA, Silvio Eder Dias; CAMARGO, Brigido Vizeu; PADILHA, Maria Itayara. A teoria das Representações Sociais nas pesquisas da enfermagem brasileira. Revista Brasileira de Enfermagem Reben, v. 5, n. 64, p. 947 - 951, set. / out. 2011. Disponível em: http://www.scielo.br/pdf/reben/v64n5/ a22v64n5.pdf. Acesso em: junho de 2018.

WALDOW, Vera Regina. O cuidado na saúde: as relações entre o eu, o outro e o cosmos. Petrópolis: Vozes, 2004.

WEBER, Max. Conceitos Básicos de Sociologia. São Paulo: Centauro, 2002.

WOLFAT, Graziela. A retomada do protagonismo feminino no parto. IHU On-Line, v. 12, n.396, p. 11 - 
13, Jul. 2012b. Disponível em: http://www.ihuonline.unisinos.br/media/pdf/IHUOnlineEdicao396.pdf. Acesso em: agosto de 2018.

Nós, mulheres, estamos desenhadas para engravidar e parir sem nenhuma dificuldade. IHU On - Line, v. 12, n.396, p. 9 - 10, jul. 2012a [Internet]. Disponível em: http://www.ihuonline.unisinos. $\mathrm{br} / \mathrm{media} / \mathrm{pdf} / \mathrm{IHUOnlineEdicao396.pdf}$. Acesso em: agosto de 2018.

YIN, Robert K. Estudo de caso: planejamento e métodos. Porto Alegre: Bookman, 2009. 